Macedonian Pharmaceutical Bulletin, 66 (Suppl 1) 21 - 22 (2020)

Online ISSN $1857-8969$

UDC: 637.131.8.046:[546.41+546.46

DOI: 10.33320/maced.pharm.bull.2020.66.03.010

Short communication

\title{
Principal component analysis of sensory attributes of calcium- and magnesium enriched milk
}

\author{
Liljana Anastasova $^{1}$, Tanja Petreska Ivanovska ${ }^{2}$, Zoran $_{\text {Zhivikj }}{ }^{2}$, Kristina Shutevska $^{2}$, \\ Rumenka Petkovska ${ }^{1}$, Lidija Petrushevska-Tozi ${ }^{2}$ \\ ${ }^{1}$ Institute of Applied Chemistry and Pharmaceutical Analysis, Faculty of Pharmacy, \\ Ss. Cyril and Methodius University, Mother Theresa 47, 1000 Skopje, Republic of North Macedonia \\ ${ }^{2}$ Institute of Applied Biochemistry, Faculty of Pharmacy, Ss. Cyril and Methodius University, Mother Theresa 47, \\ 1000 Skopje, Republic of North Macedonia
}

\section{Introduction}

Milk and dairy products are commonly used as vehicles for mineral enrichment because of their high nutritional value, the buffering effect on digestion and absorption processes, and the positive effects on growth (Lombardi et al., 2015). However, the addition of predefined quantity of minerals to milk can induce chemical reactions that cause changes in physico-chemical and sensory properties important for milk quality leading to reduced acceptability of such products to customers (Ocak \& Rajendram, 2013).

Sensory analysis of mineral-enriched product(s) represents the ultimate method for evaluation of products quality (Schiano et al., 2017). Among the methods used, principal component analysis (PCA), a multivariate technique, is frequently applied for the investigation of the sensory attributes showing highest influence on overall acceptability of the product (Piotrowska et al., 2015).

The aim of the study was application of PCA to data obtained from sensory analysis of calcium and magnesium-enriched milk in order to investigate the most important variables affecting overall product quality.

\section{Materials and methods}

As medium for preparation of calcium- and magnesium enriched milk commercially available cow's milk was used (1.5\% fat, Alpsko, Slovenia) Accurately weighted amounts of $\mathrm{CaCl}_{2}$ and $\mathrm{MgCl}_{2}$ salts (Alkaloid, Skopje, Macedonia) were added in the range $0.1-0.5 \mathrm{~g} / 100 \mathrm{~g}$ and magnesium chloride in the range $0.02-0.1 \mathrm{~g} / 100 \mathrm{~g}$, respectively. For the preparation, magnetic steering was varied in the range 10-30 min. The amount of calcium and magnesium represents an additional supply to the recommended daily allowance for calcium (3.9, 19.4, and $11.7 \%$ ) and for magnesium $(0.8,4.0$, and $2.4 \%)$ respective to lower, upper limit and a zero level. Sensory analysis was performed by non-trained panel of 10 judges, simulating the consumers, aged 25 to 62 years. The use of non-trained personnel was due to limitations in time and financial availability, allied to the interest of simulating the behavior of a common consumer (Giune \& De Lemos, 2018).

Mineral-enriched samples were placed in plastic cups for the evaluation. Water was provided for rinsing in-between the samples. Since sensory analysis immediately after production of enriched milk may not reflect actual sensory characteristics when compared to control milk, the samples were stored in refrigerator for 1 day to allow milk

\footnotetext{
*lbogdanovska@ff.ukim.edu.mk
} 
components to interact with calcium and magnesium. The milks were served $30 \mathrm{~min}$ after removing from refrigerator in a period of 1 week. The panelists were asked to use a 9-point scale to evaluate the taste, smell, color, consistency and the overall acceptability of the samples (0-very unpleasant, 5-neither like nor dislike, 9-very pleasant) (Kaushik et al., 2015). PCA of sensory characteristics of calcium- and magnesium-enriched milk was performed in the SIMCA 14.1 software (Umetrics, Umea, Sweden).

\section{Results and discussion}

The quality expressed by sensory attributes is an important indicator of the overall quality and health safety of milk (Piotrowska et al., 2015). In this study, all samples were characterized by adequate appearance/color during the entire examination period. However, the panelists reported significant differences between the taste and consistency of the tested milk samples enriched with the highest level of calcium chloride regardless of the level of magnesium chloride as compared to control milk. These samples showed unacceptable taste and consistency even after one day of cold storage.

PCA presents the studies variables in a reduced dimensional space. The first principal component (PC1) and the further PCs are linear combinations of the original variables which preserve maximal variance of the data. The first two PCs contain most of the variance of the data whereas the other PCs are practically unimportant (Jollife \& Cadima, 2016). The PCA model of the analyzed sensory attributes of calcium and magnesium-enriched milk explained $99.5 \%$ of the variance in the data. The overall sensory quality could be described by the first two principal components, PC1 and PC2 which together explain $79.8 \%$ of data variability. Several significant correlations between the sensory attributes were found. The inspection of the loading plots of the PCA model showed that the sensory attributes smell and consistency are positioned close to each other and so are the factor taste and overall acceptability. This is in accordance with the literature finding which suggest that undesirable flavor(s)/off flavor(s)/taste in fluid milk can negatively affect milk consumption and consumer product acceptability (Yeh et al., 2017). Color was positioned by angle of $90^{\circ}$ to the other examined sensory attributes indicating that it could not be correlated with the rest of the factors in the sensory analysis. The highest positive correlations were identified between taste and overall acceptability. Positive correlations were also found between smell and consistency and overall acceptability as well as between consistency and taste.

\section{Conclusion}

The PCA analysis of sensory attributes of calcium and magnesium-enriched milk identified taste as the most influential factor for the overall acceptability. In summary, PCA could be used as an efficient tool for identification of factors/attributes of prime importance when developing a new product in order to satisfy demanding consumers.

\section{References}

Guine, R.P.F., De Lemos, E.T., 2018. Development of new dairy products with functional ingredients. J. Culin. Sci. Technol. Available at: https://doi.org/10.1080/15428052.2018.1552901.

Jollife, I.T., Cadima, J., 2016. Principal component analysis: a review and recent developments. Phylos. T. R. Soc. A. 374, Available at: https://doi.org/10.1098/rsta.2015.0202.

Kaushik, R., Sachdeva, B., Arora, S., 2015. Heat stability and thermal properties of calcium fortified milk. Cyta J. Food 13, 305-311.

Lombardi, J., Spelzini, D., Folmer Correa, A., Brandelli, A., Risso, P., Boeris, V., 2016. Milk protein suspensions enriched with three essential minerals: physicochemical characterization and aggregation induced by a novel enzymatic pool. Colloid Surface. B 140, 452-459.

Ocak, E., Rajendram, R., 2013. Fortification of milk with mineral elements, in: Preedy V., Srirajaskanthan R., Patel V. (Eds), Handbook of Food Fortification and Health. Nutrition and Health. Humana Press, New York, NY, pp. 213-224.

Piotrowska, A., Swiderski, F., Kostyra, E., KrasuskaZebrovska, M., Sadowska, A., 2015. Microbiological and sensory quality of milk on the domestic market. Pol. J. Food Nutr. Sci. 65, 261267.

Schiano, A.N., Harwood, W.S., Drake, M.A., 2017. A 100-year review: sensory analysis of milk. J. Dairy Sci. 100, 9966-9986.

Yeh, E.B., Schiano, A.N., Jo, Y., Barbano, D.M., Drake, M.A., 2017. The effect of vitamin concentrates on the flavor of pasteurized fluid milk. J. Dairy Sci. 100, 4335-4348.

Maced. Pharm. Bull. 66 (Suppl 1) 21 - 22 (2020) 